
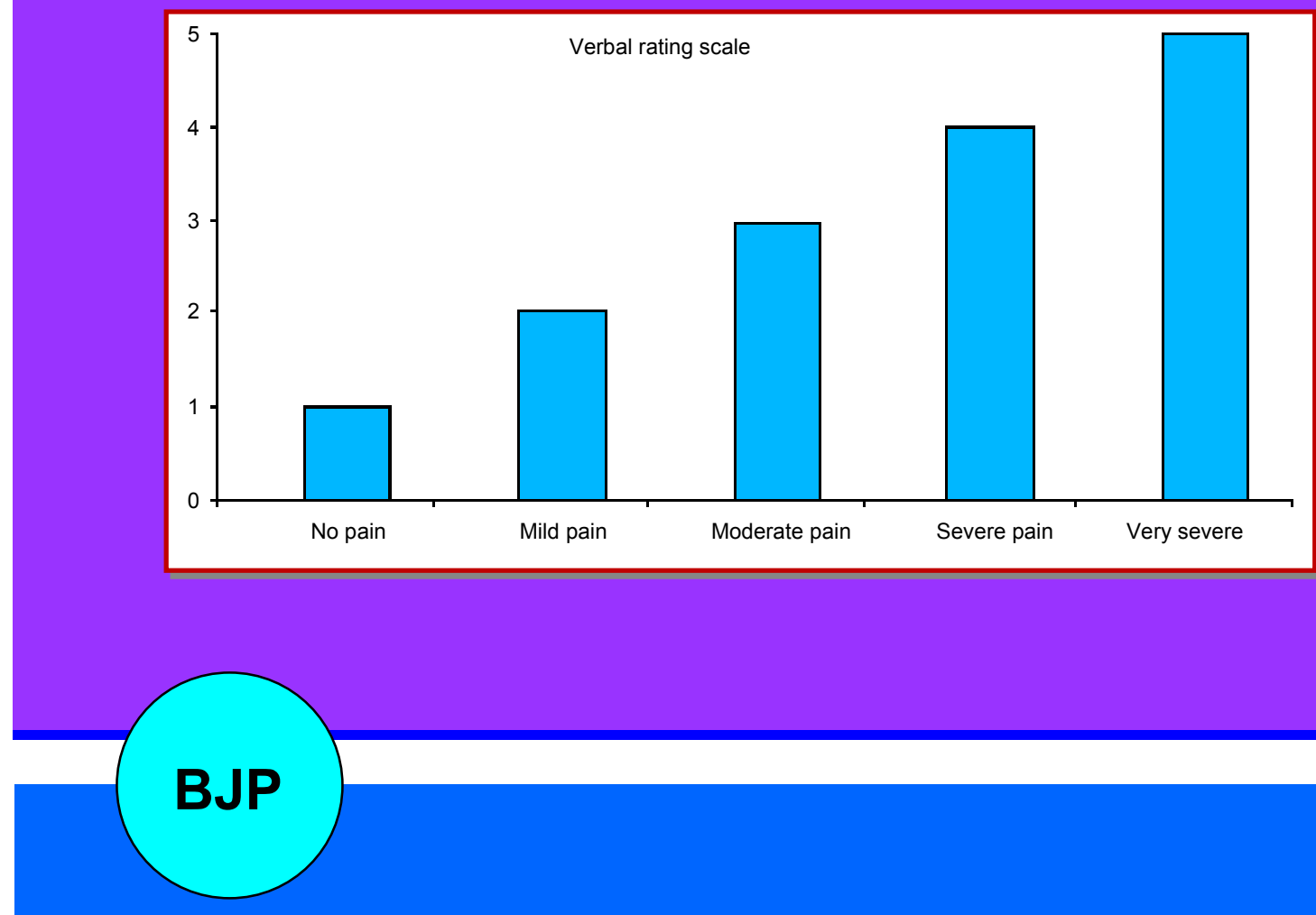

Bangladesh Journal of Pharmacology

Research Article

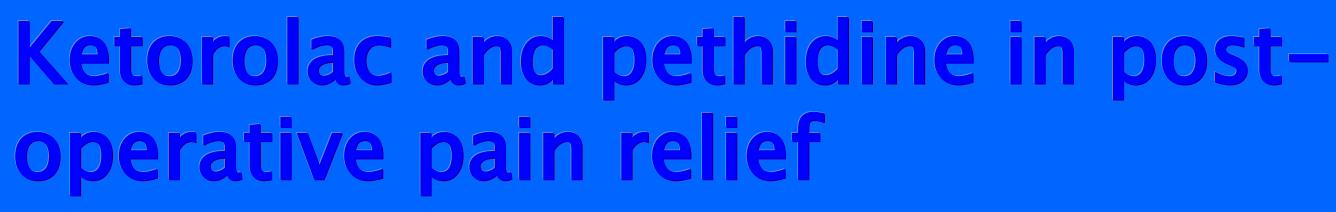


Abstracted/indexed in Academic Search Complete, Asia Journals Online, Bangladesh Journals Online, Biological Abstracts, BIOSIS Previews, CAB Abstracts, Current Abstracts, Directory of Open Access Journals, EMBASE/Excerpta Medica, Google Scholar, HINARI (WHO), International Pharmaceutical Abstracts, Open J-gate, Science Citation Index Expanded, SCOPUS and Social Sciences Citation Index;

ISSN: $1991-0088$

\title{
Ketorolac and pethidine in post-operative pain relief
}

\author{
Md. Burhan Uddin', A.K.M. Mosharrof Hossain², Meer Mahbubul Alam3 and A.Z.M. \\ Shakhawat Hossain 3
}

${ }^{1}$ Department of Pharmacology, J.R.R. Medical College, Sylhet 3100; ${ }^{2}$ Department of Pharmacology, Sylhet M.A.G. Osmani Medical College, Sylhet 3100; ${ }^{3}$ Department of Surgery, Sylhet M.A.G. Osmani Medical College, Sylhet 3100, Bangladesh.

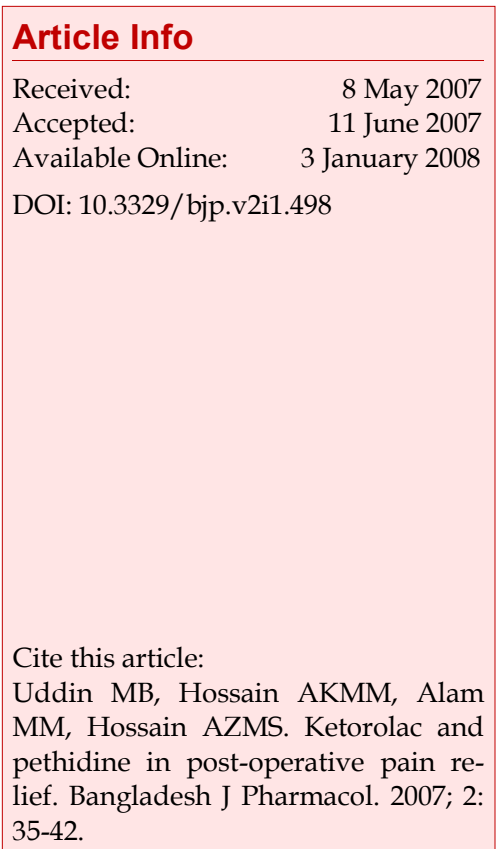

\begin{abstract}
The study was designed to compare the analgesic efficacy and safety of ketorolac and pethidine in pain relief after major surgeries. A prospective, interventional study was conducted on 71 patients undergoing major surgical intervention. Thirty six patients received ketorolac $(15 \mathrm{mg}$, intramuscularly 6 hourly) and the rest 35 patients received pethidine (100 mg, intramuscularly 6 hourly) for 48 hours post-operatively. Analgesic efficacy and safety of ketorolac were compared with that of pethidine after 1, 6, 12, 24, 32 and 48 hours of drug administration. Analgesic efficacy was measured using Visual Analogue Scale (VAS) and Verbal Rating Scale (VRS). Safety of the drugs was assessed by using sedation score and also recording adverse drug events. Ketorolac showed equianalgesic effect as pethidine estimated by VAS score at 12th and 48th hour and by VRS score at 1st and 48th hour of post-operative period. In other periods of observation, pethidine exhibited better analgesic effects than ketorolac. Ketorolac was better tolerated than pethidine and had less adverse effects compared to pethidine. This study showed that postoperative pain during the first 48 hours can be relieved by either ketorolac or pethidine. Ketorolac appeared safer than pethidine while pethidine appeared more effective analgesic than ketorolac in the management of post-operative pain. Further studies including double-blind randomized trial have been suggested to confirm the present study.
\end{abstract}

\section{Introduction}

Surgical operations are associated with pain, which may amplify endocrine and metabolic responses, autonomic reflexes, nausea, ileus and muscle spasm and thereby may increase post-operative morbidity and mortality (Kehlet, 1999). Optimal post-operative pain treatment is therefore mandatory to enable early mobilization and rehabilitation, to enhance recovery and to reduce morbidity. Despite continuous advances in anesthesia and post-operative pain management, however, reviews of the literature showed that there are still a significant number of patients who experience severe or moderate pain after surgery (Kuhn et al., 1990; Bruster et al., 1994; Oates et al., 1994).

In spite of availability of effective methods of controlling acute pain, the efficacious treatment of postoperative pain is a serious deficiency in modern health care (Porter and Jick, 1980). A number of drugs are available for post-operative pain management. In addition to opioids, effectiveness of non-steroidal antiinflammatory drugs (NSAIDs), e.g. ketorolac, diclofenac, ibuprofen, indomethacin, tenoxicam in managing 
of post-operative pain has been confirmed (James and Justins, 2003). Ketorolac often provide effective pain relief in several conditions. The advantages of the earliest possible administration of NSAIDs have been claimed by Seymour and Walton (1984). Ketorolac tromethamine having prolonged analgesic activity (Power et al., 1990), has neither sedative nor anxiolytic properties (Brown et al., 1990). Ketorolac does appear to have significant analgesic efficacy and has been used successfully to replace opioid in some situation involving mild to moderate post surgical pain. When used with an opioid it may decrease the opioid requirement by 25-50\% (Furst and Munster, 2004). Ketorolac has been shown to reduce opioid consumption by $35-66 \%$ after orthopedic surgery when compared with placebo (Kinsella et al., 1992). It provided effective analgesia that was superior to placebo and at least comparable with pethidine after orothopedic surgery.

Results from early clinical trials showed that ketorolac was as effective as morphine for post-operative pain relief after major surgery (Yee et al., 1986; Stouten et al., 1992). Pain relief was achieved earlier with ketorolac and tramadol though equianalgesic effects were found in ketorolac, tramadol and diclofenac (Swadia and Shah, 1999). As a non-narcotic alternative to pethidine it was associated with lower overall resource cost per patient of cholecystectomy (Trotter et al., 1993). Intramuscular ketorolac was significantly more effective than pethidine in reducing pain in renal colic (Larkin et al., 1999). Ketorolac is also a safe and effective supplement to opioid based analgesia for pain control after partial nephrectomy (Diblasio et al., 2004). In a study conducted among the patients of major surgeries in Bangladesh showed that intramuscular ketorolac has more analgesic effect than diclofenac for post-operative pain relief while taking pethidine as a control (Hossain, 2003). However, the availability of data related to efficacy and safety of ketorolac in post-operative pain in our population is not adequate. In addition, no comparative study has been conducted to see the analgesic efficacy and safety between ketorolac and pethidine after major abdominal surgery and mastectomy in our country.

The prolong efficacy of intramuscular ketorolac combined with reduced risk of respiratory depression suggest an important use of this drug for the relief of post-operative pain (Stanski et al., 1990). If the analgesic effect of ketorolac is closer to pethidine then it can be replaced in stead of pethidine which may be safer when adverse effects are considered.

With this background, this study was designed to compare the analgesic efficacy and safety of ketorolac and pethidine in post-operative pain relief after major surgeries.

\section{Materials and Methods}

A prospective interventional study was carried out during the period of July 2005 to June 2006. The patients admitted in the Department of Surgery and underwent cholecystectomy, laparotomy, nephrolithotomy, nephrectomy and mastectomy were taken as sample as per inclusion and exclusion criteria designed for the study.

The study participants $(\mathrm{n}=71)$ were divided into two groups viz ketorolac group $(\mathrm{n}=36)$ and pethidine group $(n=35)$ on a consecutive basis. Ketorolac group received $15 \mathrm{mg}$ ketorolac IM at the end of operation and 6 hourly for 48 hours in the post-operative period. Pethidine group received pethidine $(100 \mathrm{mg}$, intramuscularly) at the end of operation and 6 hourly for 48 hours in the post-operative period. Analgesic efficacy of both drugs in the groups was measured by Visual Analogue Scale (VAS) and Verbal Rating Scale (VRS). The safety of the drugs were measured by sedation score and also by inquiring about adverse events like nausea, vomiting, dryness of mouth, injection site pain, abdominal pain, heart burn and edema. VAS, VRS and sedation score were recorded at 1, 6, 12, 24, 32 and 48 hours post-operatively. Adverse events were recorded at the time of recording of other parameters or as soon as patient complains of them.

\section{Visual Analogue Scale (VASWall, 1998; James and Justins, 2003)}

In this technique, a $10 \mathrm{~cm}$ long scale ranged from 0-10 marks was shown to the patients where 0 marks represents no pain and 10 mark represents worst possible pain. Patient was explained to represent at ' 0 ' for "no pain at all" and at the '10' for "pain as bad as could possibly imagine" and was asked to mark the point of the scale where his/her pain lies which corresponds to the numerical index of the severity of the pain (Figure 1).

Verbal Rating Scale (VRS; Tarkkila and Saarnivaara, 1999; McCaffery et al., 1999)

There are two types of VRS in use. The 4 and 5 point VRS. In case of 4 point VRS, the marks $0=$ no pain, $1=$ 


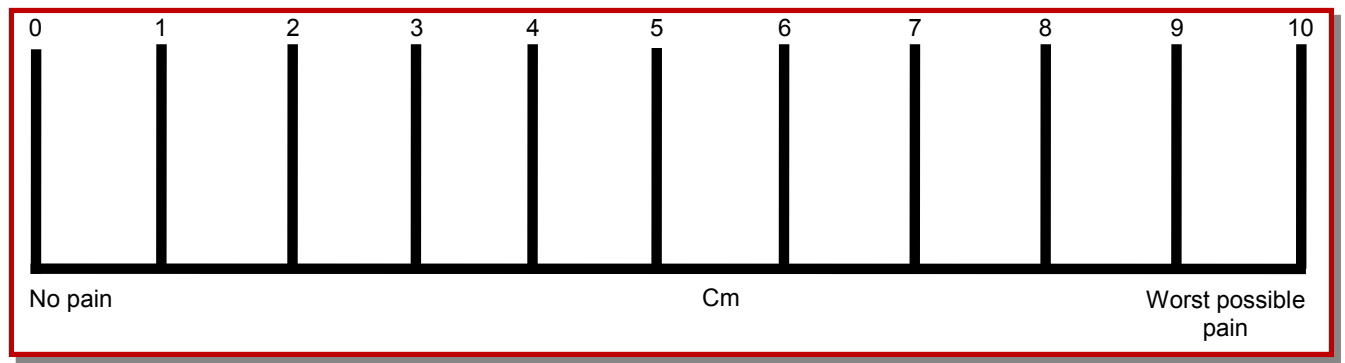

Figure 1: Visual analogue scale

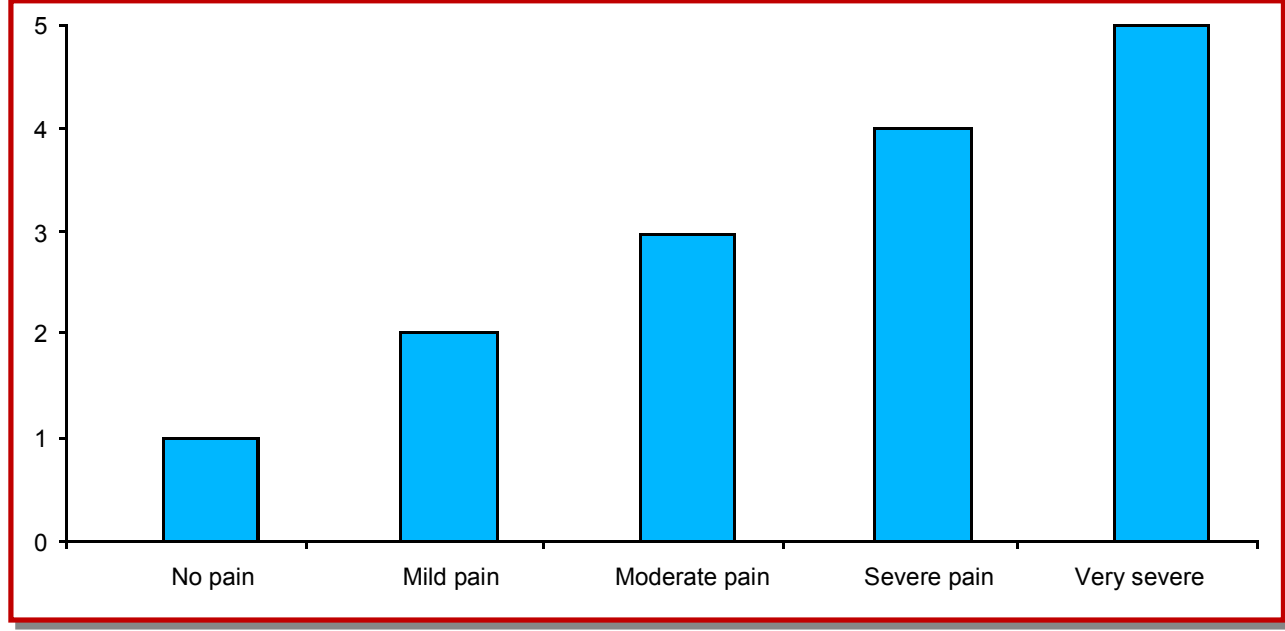

Figure 2: Verbal Rating Scale

mild pain, 2 = moderate pain, $3=$ severe pain. According to 5 point VRS, the marks $1=$ no pain, $2=$ mild pain, $3=$ moderate pain, $4=$ severe pain, $5=$ very severe pain/over whelming pain (the worst pain you can imagine). 5 point VRS was employed in this study (Figure 2). Here the patients were asked to describe the degree of their discomfort by choosing one of the vertical lines that corresponds to the intensity of pain that they were feeling.

\section{Sedation score (Aitkenhead et al., 1998)}

Increased sedation score indicate the less sedative effect of drug. Sedation score was evaluated on a scale 0 to 4; $0=$ asleep and not rousable, 1 = asleep but rousable, 2 = drowsy, and 3 = awake and not alert or tense, $4=$ awake and alert or tense.

Data were collected through a data collection sheet, by observation using questionnaire and by clinical examination. Statistical analysis was done as mean \pm standard deviation (SD) for quantitative variables and percentage was calculated for qualitative variables. Difference between two independent groups was compared by unpaired student's t-test using SPSS for windows versions 10.0. $\mathrm{p}$ value less than 0.05 were considered statistically significant.

The study was approved by the Ethics Review Committee of Sylhet M. A. G. Osmani Medical College. Informed written consent was taken from all participants prior to study.

\section{Results}

The study was carried out on 32 male and 39 female patients with age ranged between 20-65 years. Mean ( \pm SD) age of both ketorolac- (41.1 \pm 10.9 years $)$ and pethidine- (39.6 \pm 10.9 years) treated group did not differ. Table I shows the nature of surgical operations among study samples. Cholecystectomy was most frequently performed operation among the study groups. The other performed operations were laparotomy, nephrolithotomy, nephrectomy and mastectomy.

VAS score has been depicted in Table II. At 1st hour VAS score was recorded as $46.3 \pm 5.6$ and $42.3 \pm 5.6$ in the ketorolac-treated and pethidine-treated group respectively. The difference between these two groups is statistically significant $(p<0.01)$. At 6 th hours after administration of drugs, VAS score reduced to $37.8 \pm$ 
Table I

\begin{tabular}{|c|c|c|c|}
\hline \multicolumn{4}{|c|}{$\begin{array}{c}\text { Type of operations where ketorolac and pethidine } \\
\text { used }\end{array}$} \\
\hline \multirow[t]{2}{*}{$\begin{array}{l}\text { Name of opera- } \\
\text { tions }\end{array}$} & \multicolumn{2}{|c|}{$\begin{array}{c}\text { Number of patients treated } \\
\text { by }\end{array}$} & \multirow[t]{2}{*}{ Total } \\
\hline & Ketorolac & Pethidine & \\
\hline Cholecystectomy & 22 & 13 & 35 \\
\hline Laparotomy & 8 & 11 & 19 \\
\hline Nephrolithotomy & 4 & 5 & 9 \\
\hline Nephrectomy & 1 & 3 & 4 \\
\hline Mastectomy & 1 & 3 & 4 \\
\hline
\end{tabular}

Table II

Assessment of post-operative pain relief by VAS

\begin{tabular}{|l|c|c|}
\hline Time period & Ketorolac-treated & Pethidine-treated \\
\hline After 1 hour & $46.3 \pm 5.6$ & $42.3 \pm 5.6^{\mathrm{a}}$ \\
After 6 hours & $37.8 \pm 11.5$ & $31.7 \pm 11.3^{\mathrm{a}}$ \\
After 12 hours & $33.3 \pm 7.6$ & $30.0 \pm 7.9^{\mathrm{NS}}$ \\
After 24 hours & $31.4 \pm 9.6$ & $26.3 \pm 8.1^{\mathrm{b}}$ \\
After 32 hours & $28.5 \pm 9.6$ & $22.7 \pm 8.7^{\mathrm{b}}$ \\
After 48 hours & $13.1 \pm 7.3$ & $11.7 \pm 4.5^{\mathrm{NS}}$ \\
\hline
\end{tabular}

Data are expressed as mean $\pm \mathrm{SD}$; aSignificance of difference between ketorolac and pethidine group at $\mathrm{p}<0.01$; bSignificance of difference between ketorolac and pethidine group at $\mathrm{p}<0.05 ; \mathrm{NS}=$ No significance of difference between ketorolac and pethidine treated groups

\section{Table III}

\section{Assessment of post-operative pain relief by VRS}

$$
\text { score }
$$

\begin{tabular}{|lcc|}
\hline Time & Ketorolac-treated & Pethidine-treated \\
\hline After 1 hour & $3.1 \pm 0.4$ & $3.0 \pm 0.2^{\mathrm{NS}}$ \\
After 6 hours & $3.0 \pm 0.5$ & $2.1 \pm 0.4^{\mathrm{a}}$ \\
After 12 hours & $2.7 \pm 0.7$ & $2.2 \pm 0.7^{\mathrm{a}}$ \\
After 24 hours & $2.7 \pm 0.7$ & $1.9 \pm 0.8^{\mathrm{b}}$ \\
After 32 hours & $2.3 \pm 0.7$ & $1.9 \pm 0.5^{\mathrm{c}}$ \\
After 48 hours & $1.3 \pm 0.6$ & $1.2 \pm 0.6$ \\
\hline
\end{tabular}

Data are expressed as mean $\pm \mathrm{SD}$; aSignificance of difference between ketorolac and pethidine group at $\mathrm{p}<0.01$; bSignificance of difference between ketorolac and pethidine group at $p<0.001$ : cSignificance of difference between ketorolac and pethidine group at $\mathrm{p}<0.05$; NS $=$ No significance of difference between ketorolac and pethidine treated groups

11.5 and $31.7 \pm 11.3$ in the ketorolac-treated and pethidine-treated groups respectively. The difference between these two groups was statistically significant $(p<0.01)$. Pethidine showed more pronounced analgesic effects after one and six hours of administration.

However, the VAS score did not differ after 12 hours of estimation $(p>0.05)$. The VAS scores after 24 and 32 hours after administration were statistically significant $(p<0.05)$. At the 48th hours, the VAS score did not differ after 12 hours of estimation ( $p>0.05)$.

After 1 hour, VRS scores were recorded as $3.1 \pm 0.4$ in ketorolac-treated group while it was recorded as $3.0 \pm$ 0.2 in pethidine-treated group (Table III). VRS scores in the treatment group did not differ after 1 hour of estimation $(\mathrm{p}>0.05)$.

The result shows the comparable analgesic effect of two drugs after 1 hour. At 6th hours, VRS score was recorded as $3.0 \pm 0.5$ and $2.1 \pm 0.4$ in the ketorolactreated and pethidine-treated groups respectively. The difference between these two groups was highly significant $(p<0.001)$. At 12th hour, VRS scores were recorded as $2.7 \pm 0.7$ in ketorolac-treated group while it was recorded as $2.2 \pm 0.7$ in pethidine-treated group. The difference between these two groups was statistically significant $(\mathrm{p}<0.01)$. At 24 th hour, VRS score was recorded as $2.7 \pm 0.7$ and $1.9 \pm 0.8$ in the ketorolactreated and pethidine-treated groups respectively. The difference between these two groups was highly significant $(\mathrm{p}<0.001)$.

However, at 32th hour, VRS scores were recorded as 2.3 \pm 0.7 in ketorolac-treated group while it was recorded as $1.9 \pm 0.5$ in pethidine-treated group. The difference between these two groups was statistically significant $(p<0.05)$. The results show that pethidine exhibits more analgesic effects after 6, 12, 24, 32 hours of administration. Analgesic effects of pethidine after 6 and 24 hours were most pronounced $(p<0.001)$ than after 12 and 32 hours. However, after 32 hours analgesic effect of pethidine was less pronounced than that as was estimated after 6, 12 and 24 hours $(p<0.05)$. At 48 th hour, VRS scores were recorded as $1.3 \pm 0.6$ in ketorolac -treated group while it was $1.2 \pm 0.6$ in pethidinetreated group. VRS scores in the treatment group did not differ after 12 hours ( $p>0.05)$. The result shows the comparable analgesic effect of two drugs after 48 hours.

The sedation scores after 1, 6, 12, 24, 32 and 48 hours are depicted in Table IV. One hour after administration of drug, sedation score was recorded as $2.9 \pm 0.4$ in ketorolac-treated group while it was recorded as $2.7 \pm$ 0.5 in pethidine-treated group. Sedation score in treated groups did not differ after 1 hour of estimation $(\mathrm{p}>0.05)$.

Six hours after administration of drugs sedation score was recorded as $2.8 \pm 1.1$ and $1.6 \pm 0.6$ in the ketorolactreated and pethidine-treated group respectively. The 
Table IV

Assessment of sedative effect by sedation score estimated after drug administration in postoperative pain relief

\begin{tabular}{|l|cc|}
\hline Time & Ketorolac-treated & Pethidine-treated \\
\hline After 1 hour & $2.9 \pm 0.4$ & $2.7 \pm 0.5^{\mathrm{NS}}$ \\
After 6 hours & $2.8 \pm 1.1$ & $1.6 \pm 0.6^{\mathrm{a}}$ \\
After 12 hours & $2.7 \pm 1.0$ & $1.7 \pm 0.8^{\mathrm{a}}$ \\
After 24 hours & $2.6 \pm 0.8$ & $1.8 \pm 0.7^{\mathrm{a}}$ \\
After 32 hours & $2.9 \pm 1.0$ & $1.5 \pm 0.6^{\mathrm{a}}$ \\
After 48 hours & $2.8 \pm 1.0$ & $1.3 \pm 0.5^{\mathrm{a}}$ \\
\hline
\end{tabular}

Data are expressed as mean $\pm \mathrm{SD}$; aSignificance of difference between ketorolac and pethidine group at $\mathrm{p}<0.001$; NS $=$ No significance of difference between ketorolac and pethidine treated groups

Table V

Adverse effects during the course of treatment

\begin{tabular}{|c|c|c|}
\hline \multirow[t]{2}{*}{ Symptoms } & \multicolumn{2}{|c|}{ Number of patients } \\
\hline & $\begin{array}{c}\text { Ketorolac-treated } \\
(\mathrm{n}=36)\end{array}$ & $\begin{array}{l}\text { Pethidine-treated } \\
\quad(\mathrm{n}=35)\end{array}$ \\
\hline Nausea & $\begin{array}{r}2 \\
(5.55)\end{array}$ & $\begin{array}{r}2 \\
(5.71)\end{array}$ \\
\hline Vomiting & 0 & $\begin{array}{r}11 \\
(31.4)\end{array}$ \\
\hline $\begin{array}{l}\text { Nausea and vom- } \\
\text { iting }\end{array}$ & 0 & $\begin{array}{r}11 \\
(31.4)\end{array}$ \\
\hline Dry mouth & $\begin{array}{r}1 \\
(2.8)\end{array}$ & $\begin{array}{r}11 \\
(31.4)\end{array}$ \\
\hline Heart burn & 0 & 0 \\
\hline Abdominal pain & 0 & 0 \\
\hline Mild edema & $\begin{array}{r}6 \\
(16.7)\end{array}$ & 0 \\
\hline Injection site pain & $\begin{array}{r}1 \\
(2.8)\end{array}$ & 0 \\
\hline Total & $\begin{array}{r}10 \\
(27.8)\end{array}$ & $\begin{array}{r}35 \\
(100)\end{array}$ \\
\hline
\end{tabular}

' 0 ' indicate events not seen; Value in parenthesis shows percentage

difference between these two groups was highly significant $(\mathrm{p}<0.001)$.

After 12 hours of administration of drug, sedation score was recorded as $2.7 \pm 1.0$ in ketorolac-treated group while it was recorded as $1.7 \pm 0.8$ in pethidine-treated group. The difference between these two groups was highly significant $(\mathrm{p}<0.001) .24$ hours after administration of drugs sedation score was recorded as $2.6 \pm 0.8$ and $1.8 \pm 0.7$ in the ketorolac-treated and pethidinetreated group respectively. The difference between these two groups is highly significant $(\mathrm{p}<0.001)$. After 32 hours, sedation score was recorded as $2.9 \pm 1.0$ in ketorolac-treated group while it was recorded as $1.5 \pm$ 0.6 in pethidine-treated group. The difference between these two groups was highly significant $(p<0.001) .48$ hours after administration of drugs sedation score was recorded as $2.8 \pm 1.0$ and $1.3 \pm 0.5$ in the ketorolactreated and pethidine-treated group respectively. The difference between these two groups was highly significant $(p<0.001)$. The results show that pethidine showed more pronounced sedative effects after 6, 12, 24, 32 and 48 hours of administration.

Other adverse effects of ketorolac and pethidine were shown in Table V. All (100\%) of the pethidine-treated group experienced some sorts of adverse effects while $27.8 \%$ of ketorolac-treated patients experienced adverse effects. $5.6 \%$ of ketorolac treated patients and $5.7 \%$ of pethidine-treated patients experienced nausea. $31.4 \%$ of pethidine-treated patients experienced vomiting while none of ketorolac-treated patient vomited. $31.4 \%$ of pethidine-treated patients complaint of dry mouth while one patient had dry mouth in ketorolac-treated group.

Mild edema developed in $16.7 \%$ in ketorolac-treated patient while none developed edema in pethidinetreated patients.

\section{Discussion}

This study showed that intramuscular ketorolac is safer than intramuscular pethidine in post-operative pain relief after major surgery and also suggested that the analgesic effect of intramuscular ketorolac is comparable with the effect of pethidine in same postoperative setting.

The VAS and VRS are valid, reliable and appropriate instruments for quantifying pain (Williamson and Hoggart, 2005) and could be used concomitantly (Carborg et al., 1987; Sandhu et al., 1994, Tarkilla and Saarnivaara, 1999; Smith et al., 2000) or separately (Stanski et al., 1990, Larkin, 1999) for pain measurement. The VAS has more practical limitations than VRS. The limitations are it is time consuming, requires ability to understand the abstract concept of the VAS line and then relate it to distance from a zero mark (Cork et al., 2004). VRS is preferred to VAS but it lacks sensitivity and data it produces can be misunderstood (Williamson and Hoggart, 2005). Therefore, in this series both VAS and VRS were used as the pain measuring instruments. The safety of the drugs was evaluated by sedation score and the adverse 
events experienced by the patients in the study period.

Ketorolac is a newer NSAIDs used in the management of moderate to severe post-operative pain. Common side effects include dizziness, headache, gastrointestinal pain, dyspepsia, edema, nausea and pain at the site of injection (Smith et al., 2000). Pethidine is a commonly used post-operative analgesic, having side effects like nausea, vomiting, sedation and dryness of mouth (Schumacher et al., 2004).

In this series, all patients of pethidine-treated group had some adverse effects. Among them 5.7\% complained nausea, $31.4 \%$ complained of vomiting, and $31.4 \%$ complained of both nausea and vomiting. In Hossain (2003) study, the incidence of nausea and vomiting was $32 \%$ which was almost similar to this observation. This nausea and vomiting was not related to GIT upset but it was attributed to pharmacological action of pethidine which stimulates the chemoreceptor trigger zone (CTZ) in the area postrema that is influenced by the chemicals in both blood and cerebrospinal fluid (Aitkenhead et al., 1998a). 31.4\% patients complained of dry mouth that was due to antimuscarinic effects of pethidine (Schumacher et al., 2004).

Adverse effects of ketorolac in this series were nausea $(5.6 \%)$, injection site pain $(2.8 \%)$, and mild oedema $(16.7 \%)$. However, vomiting and abdominal pain was not complained by the patients of ketorolac group which may be due to the use of antiulcer, antimuscarinic drugs during perioperative period. Tarkkila and Saarnivaara (1999) found nausea in 47\%, injection site pain $16 \%$, vomiting in $26 \%$ and abdominal pain in $11 \%$ of patients. The higher incidence of adverse effects may be due to higher dose of ketorolac in their study. Abdominal pain may be caused by uninhibited acid secretion, reduced mucous and $\mathrm{HCO}_{3}$ secretion, reduced mucosal blood flow and biochemical bridging of mucous barrier allowing the $\mathrm{H}^{+}$to enter the mucosal cell (James and Justins, 2003). A mild edema was observed in $16.7 \%$ patients which was transitory may be due to fluid and water retention of ketorolac as common side effects of NSAIDs (Aitkenhead et al., 1998). Injection site pain was due to local irritation.

There was no significant difference of sedation score after 1 hour between ketorolac and pethidine group probably due to the sedative effect of anesthetic drugs which is most prominent in early hours. In subsequent hours of observations that are in 6, 12, 24, 32 and 48 hours which showed significant difference of sedation score between ketorolac and pethidine. This suggests that pethidine had pronounced sedative effect. This is due to depressant pharmacological action of pethidine on central nervous system (CNS) which was similar with observation of Hossain (2003) and to that reported by Smith et al. (2000).

There was significant difference of VAS score between ketorolac and pethidine after 1, 6, 24 and 32 hours. Though there was no difference of analgesic effect between ketorolac and pethidine at 12 and 48 hours, but there was significant difference at 1, 6, 24 and 32 hours. In our study the findings are more in favour of better analgesic effect of pethidine as evaluated by VAS score, in comparison with ketorolac. Hossain (2003) observed similar findings of significant difference of analgesic effect between ketorolac and pethidine after 24 and 32 hours evaluated by VAS score.

Shende and Das (1999) observed in post-operative pediatrics surgery that ketorolac was as effective as pethidine regarding post-operative analgesic effect. The finding of Abbas et al. (2004) was not similar to our findings. They found that there was no significant difference in post-operative pain relief between ketorolac and pethidine at any time interval in postoperative period.

There was significant difference of VRS score between ketorolac and pethidine after 6, 12, 24 and 32 hours. This finding was also similar with observation of Hossain (2003) who found significant difference of analgesic effect by VRS score at 24 and 32 hours. At 1 hour- no significant difference was probably due to initial delay of onset of action of both drugs and at 48 hours- equianalgesic effect may be showed to both drugs. Hossain (2003) observed significant difference of analgesic effect between ketorolac and pethidine after 48 hours. This finding was not similar with our observation.

With this observation, considering VAS and VRS, pethidine seems to have better analgesic effect than ketorolac. Considering adverse effects, ketorolac is safer than pethidine having much less sedation and adverse events.

On the basis of this prospective interventional (consecutive) open label clinical study, first 48 hours of postoperative pain can be managed by ketorolac or pethidine. This study also suggested that ketorolac was safer than pethidine in managing post-operative pain. However, the analgesic efficacy of ketorolac was comparable to pethidine, though pethidine had overall better analgesic effect than ketorolac. 
Considering all parameters of the study we may conclude that ketorolac is comparable to pethidine for its analgesic effect and it is safer than pethidine in postoperative pain relief. Therefore, ketorolac may be an alternative to pethidine in post-operative pain relief. The limitation of the study was subjective assessment of pain by the patients and lack of randomization. As patients were not randomized, a degree of subjective biasness may be present. Therefore, prospective longitudinal randomized double- blind studies should be designed for better assessment of analgesic efficacy and adverse effects between these two drugs and also combination use of ketorolac and pethidine.

\section{References}

Abbas SM, Kamal RS, Afshan G. Effect of ketorolac on postoperative pain relief in dental extraction cases- a comparative study with pethidine. J Pak Med Assoc. 2004; 54: 319-22.

Aitkenhead AR, Rowbotham DJ, Smith G. Analgesic drugs. In: Textbook of anesthesia. 4th ed, Spain, Churchill Livingstone, 1998a, pp 211-22.

Brown CR, Mazzulla JP, Mok MS, Nussdorf RT, Robin PD, Schwesinger $\mathrm{WH}$. Comparison of repeat doses of intramuscular ketorolac tromethamine and morphine sulphate for analgesia after major surgery. Pharmacotherapy 1990; 10: S45 -50 .

Bruster S, Jarman B, Bosanquet N, Weston D, Erens R, Delbanco TL. National survey of hospital patients. BMJ. 1994; 309: 1542-46.

Carborg L, Lindoff C, Hellman A. Diclofenac versus pethidine in the management of pain after hysterectomy. Eur J Anaesthesiol. 1987; 4: 241-47.

Cork RC, Isaac I, Elsharydah A, Saleemi S, Zavisca F, Alexander L. A comparison of the verbal rating scale and the visual analog scale for pain assessment. Internet J Anesthesiol. 2004; 8: 50-52.

Diblasio CJ, Snyder MF, Kalton MW. Ketorolac: Safe and effective analgesia for the management of renal cortical tumors with partial nephrecotomy. J Urol. 2004; 171: 1062-65.

Furst D, Munster T. Non-steroidal anti-inflammatory drugs, disease modifying antirheumatic drugs, non-opioids analgesics and drugs used in gout. In: Basic and clinical pharmacology, Ketzung BG (eds), 9th ed, Singapore, McGraw Hill, 2004, pp 596-623.

Hossain MS. Comparative study between intramuscular ketorolac and intramuscular diclofenac for management of post-operative pain. Comilla BMA Med J. 2003; 10: 58-62.

James D, Justins D. Acute post-operative pain. In: Wyllie and
Churchill Davidson's: A practice of anesthesia, Healy TEJ, Knight PR (eds), 7th ed, India, Arnold, 2003, pp 1213-34.

Kehlet $\mathrm{H}$. Acute pain control and accelerated post-operative surgical recovery. Surg Clin N Am. 1999; 79: 431-43.

Kinsella J, Moffat AC, Patrick JA, Prentice JW, McArdle CS, Kenny GN, et al. Ketorolac trometamol for post-operative analgesia after orthopaedic surgery. Br J Anaesth. 1992; 69: 19-22.

Kuhn S, Cooke K, Collins M, Jones JM, Mucklow JC. Perceptions of pain relief after surgery. BMJ. 1990; 300: 168790.

Larkin GL, Peacock WF, Pearl SM, Blair GA, D'Amico F. Efficacy of ketorolac tromethamine versus pethidine in the ED treatment of acute renal colic. Am J Emerg Med. 1999; 17: 6-10.

McCaffery M, Pasero F, Pasero C. Pain assessment tools. In: Pain: Clinical manual, McCaffery M, Pasero C (eds), 2nd ed, St. Louis, Mosby, 1999, p 63.

Oates JD, Snowdon SL, Jayson DW. Failure of pain relief after surgery. Attitudes of ward staff and patients to post-operative analgesia. Anaesthesia 1994; 49: 755-58.

Porter J, Jick H. Addiction rate in patients treated with opioids. N Engl J Med. 1980; 302: 123.

Power I, Noble DW, Douglas E. Comparison of intramuscular ketorolac, trometerol and morphine sulphate for pain relief and cholecystectomy. Br J Anaesth. 1990; 65: 448-55.

Sandhu DP, Iacovou JW, Fletcher MS, Kaisary AV, Philip NH, Arkell DG. A comparison of intramuscular ketorolac and pethidine in the alleviation of renal colic. Br J Urol. 1994; 74: 690-93.

Schumacher MA, Besbaum AI, Way WL. Opioid analgesic and antagonist. In: Basic and clinical pharmacology. Ketzung BG (ed), 9th ed, Singapore, McGraw Hill, 2004, p 497, 516.

Seymour RA, Walton JG. Pain control after 3rd molar surgery. Int J Oral Surg. 1984; 13: 457-85.

Shende D, Das K. Comparative effects of intravenous ketorolac and pethidine on peri-operative analgesia and post-operative nausea and vomiting (PONV) for pediatric strabismus surgery. Acta Anesthesiol Scand. 1999; 43: 265-69.

Smith LA, Carroll D, Edward JE. Single-dose ketorolac and pethidine in acute post-operative pain: Systemic review with meta-analysis. Br J Anaesth. 2000; 84: 48-58.

Stanski DR, Cherry C, Bradley R. Efficacy and safety of single doses of intramuscular ketorolac tromethamine compared with pethidine for post-operative pain. Pharmacotherapy 1990; 10: S40-44.

Stouten EM, Armbruster S, Houmes RJ, Prakash O, Erdmann W, Lachmann B. Comparison of ketorolac and morphine for post-operative pain after major surgery. Acta Anaesthesiol 
Scand. 1992; 36: 716-21.

Swadia VN, Shah MB. Comparative evaluation of ketorolac, tramadol and diclofenac for post-operative pain relief in minor surgical procedures. Indian J Anaes. 1999; 43: 64-66.

Tarkkila P, Saarnivaara L. Ketoprophen, diclofenac or ketorolac for pain after tonsillectomy in adults. Br J Anaesth. 1999; 82: 56-60.

Trotter JP, Reinhart SP, Katz RM, Glazier HS. Economic assessment of ketorolac versus narcotic analgesics and post- operative pain management. Clin Ther. 1993; 15: 938-48.

Wall PD. The prevention of post-operative pain. Pain 1998; 33: 289-90.

Williamson A, Hoggart B. Pain: A review of three commonly used pain rating scales. J Clin Nursing. 2005; 14: 798-804.

Yee JP, Brown CR, Allbon C, Koshiver JE. Analgesia from intramuscular ketorolac tromethamine compared to morphine in severe pain following major surgery. Pharmacotherapy 1986; 6: 253-61. 